\title{
Spatial and Temporal Trends in Sunshine Duration over Western Europe (1938-2004)
}

\author{
ARTURO SANCHEZ-LORENZO \\ Group of Climatology, University of Barcelona, Barcelona, Catalonia, Spain \\ Josep CALbÓ \\ Department of Physics and Institute of the Environment, University of Girona, Girona, Catalonia, Spain \\ JAVIER MARTIN-VIDE \\ Group of Climatology, University of Barcelona, Barcelona, Catalonia, Spain
}

(Manuscript received 23 January 2008, in final form 7 May 2008)

\begin{abstract}
This work analyzes sunshine duration variability in the western part of Europe (WEU) over the 19382004 period. A principal component analysis is applied to cluster the original series from 79 sites into 6 regions, and then annual and seasonal mean series are constructed on regional and also for the whole WEU scales. Over the entire period studied here, the linear trend of annual sunshine duration is found to be nonsignificant. However, annual sunshine duration shows an overall decrease since the 1950s until the early 1980s, followed by a subsequent recovery during the last two decades. This behavior is in good agreement with the dimming and brightening phenomena described in previous literature. From the seasonal analysis, the most remarkable result is the similarity between spring and annual series, although the spring series has a negative trend; and the clear significant increase found for the whole WEU winter series, being especially large since the 1970s. The behavior of the major synoptic patterns for two seasons is investigated, resulting in some indications that sunshine duration evolution may be partially explained by changes in the frequency of some of them.
\end{abstract}

\section{Introduction}

Knowledge about solar radiation variability and trends is of great interest because it is a fundamental variable in the energy balance on a range of scales from global to microscale, besides its impacts on physical and biological systems, and also on the economy and society. In particular, solar radiation at the surface is an important factor in the context of recent climate change, since its variation is related to both cloudiness changes and variations in aerosol concentration (Ramanathan et al. 2001; Stanhill 2007).

Corresponding author address: Arturo Sanchez-Lorenzo, Group of Climatology, Department of Physical Geography, University of Barcelona, C/Montalegre No. 6, 08001 Barcelona, Spain.

E-mail: asanchezlorenzo@ub.edu
In the last decade, research by several authors has reported a reduction of solar radiation between the 1950s and the 1980s (see, e.g., Stanhill and Cohen 2001). This phenomenon is commonly called the "global dimming," although other authors (Gilgen et al. 1998; Liepert 2002; Alpert et al. 2005) have investigated its nonuniform spatial distribution. On the other hand, very recent studies have detected a reversal in the negative trend (i.e., a "brightening") that initiated in the late 1980s (Wild et al. 2005; Pinker et al. 2005).

Although the cause of these recent changes in solar radiation is not fully understood, currently the most accepted reason is a change in the transmissivity of the earth's atmosphere due to varying concentrations of aerosols as consequence of anthropogenic emissions (Stanhill 2005). For example, the recent brightening may be due to reductions of anthropogenic aerosol emissions during the most recent years due to air pol- 
lution regulatory actions in developed countries and also due to declining economies in most eastern European countries in the late 1980s (Streets et al. 2006).

There might be a relationship between solar radiation at the earth's surface and air temperature variations (Kaiser and Qian 2002). Thus, dimming is consistent with the hypothesis that anthropogenic aerosol cooling effect partially offset greenhouse warming over much of Eurasia during the 1960s through the 1980s (Charlson et al. 1991). In this sense, a recent paper (Wild et al. 2007) suggests that solar dimming was effective in masking greenhouse warming, but only up to the 1980s, when dimming gradually transformed into brightening, allowing the uncovered greenhouse effect to reveal its full dimension with a sharp increase of the temperatures from then on until nowadays.

Both the global dimming and the recent brightening carry uncertainty in their description and quantification (Trenberth et al. 2007). Therefore, it seems convenient to support and extend the analysis with indirect or related variables, because networks of pyranometers (for measurement of solar radiation) have in general poor spatial coverage and cover a short temporal period. Thus, other climatic variables (proxy measurements) that are well correlated with global radiation-such as evaporation, visibility, cloudiness, or sunshine duration-can be used (Stanhill 2005).

Sunshine duration (SunDu), defined as the amount of time in which direct solar radiation is above a certain threshold (usually taken at $120 \mathrm{~W} \mathrm{~m}^{-2}$ ), is one of the first approaches to radiation measurements and is inversely related to cloudiness (Angell 1990); it may also be useful in detecting long-term variation of aerosols (Kaiser and Qian 2002). The advantages of SunDu records, with respect to the other variables mentioned, are 1) that they started more than $100 \mathrm{yr}$ ago and 2) that they are much less subjective than visibility or cloudiness observations. Also, several studies have shown good correlations between SunDu and solar radiation records (e.g., Stanhill and Cohen 2005).

The generalized use of sunshine duration recorders in the global network of meteorological observatories by the end of the nineteenth century justifies a number of studies that investigate the spatial and temporal behavior of SunDu in the recent decades for different parts of the world (see Sanchez-Lorenzo et al. 2007, hereafter SL07, for a list of such studies). Nevertheless, there are few published studies, to our knowledge, about SunDu behavior on global, hemispheric, or continental scales. In particular for Europe, other than studies for single countries, we only found the works by Brázdil et al. (1994) that analyzed 26 SunDu series for different areas of central and east Europe and by Auer

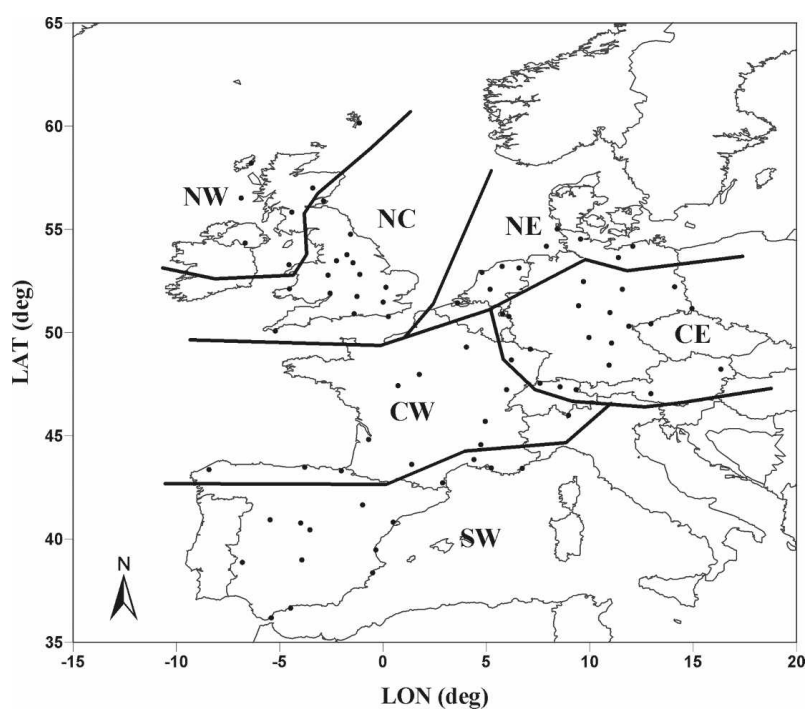

FIG. 1. Position of the stations with sunshine duration series used in this study. Approximate limits of the regions based on PCA are also indicated (bold lines).

et al. (2007) that showed some regional series for the Alpine region.

The present paper attempts to fill this gap of knowledge: our goal is to show and analyze the temporal variability and trends of SunDu in western Europe (WEU) and also in several regions within this area. The possible influence of some circulation patterns on the most relevant SunDu trend is investigated. As far as methodology and focus are concerned, the present paper may be understood as an extension of a previously published paper by the same authors (SL07) for the Iberian Peninsula.

\section{Data}

Our database comprises 79 series of daily or monthly SunDu corresponding to the same number of meteorological stations placed in seven countries that approximately cover the western half of Europe (Fig. 1). The countries and number of stations (in parenthesis) in each of them are: United Kingdom (23), Germany (18), Spain (13), France (13), the Netherlands (6), Switzerland (4), and Austria (2).

Most series were obtained directly from the databases of the European Climate Assessment \& Dataset project (ECA\&D; Klein Tank et al. 2002). Twenty-one series for Great Britain and the only one for Northern Ireland were obtained from the archives of the Met Office Historic Station Data; the series for Gibraltar was built combining data from the Met Office and other complementary data supplied by Professor Dennis Wheeler (Wheeler 2001). Finally, for Spain, six series are taken directly from the ECA\&D, another three se- 
ries were built from data supplied by the Instituto Nacional de Meteorología (INM), and four series were composed by combining data from the two sources (SL07). The ECA\&D and Met Office archives contain data for many more stations, but we only considered the series with more than $40 \mathrm{yr}$ of continuous records and that contain a complete record for the 1961-90 period.

Series from Met Office are in monthly resolution, while all the other data were available as daily SunDu. The quality of the series used is in part assured because the data come from sources (ECA\&D, INM, Met Office) that already apply some quality control checks. However, we also applied a number of additional checks, and following the recommendations by Aguilar et al. (2003) we tried to 1) detect, correct, and/or remove gross errors, such as aberrant (more hours registered than the maximum possible) or negative values; 2) confirm the consistency of calendar dates (days per month and year); and 3) remove false zeros.

The absolute monthly SunDu was obtained, for the ECA\&D and INM series, by adding the corresponding daily values. When more than 6 days in a month were missing, we did not compute the monthly value, and the whole month was set as missing. When 6 or fewer days were missing, the total SunDu for the corresponding month was obtained by adequately correcting the sum of the available days on the basis of the number of missing values.

In general, we could not obtain information about the instrument used for measuring SunDu; however we assume that most data included in the database were measured by Campbell-Stokes heliographs. In fact, only few stations (from the ECA\&D database; J. Verkaik 2006, personal communication) may have used other sunshine duration recorders in recent years, and consequently only these years can be suspicious.

\section{Regionalization and regional series construction}

As in SL07, the regionalization approach is based on a principal component analysis (PCA) in s-mode, starting from the correlation matrix, which is calculated considering the data from the 12 months of the year. Specifically, monthly normalized anomalies were used, where anomalies for each station series are defined as differences to the 1961-90 mean and normalized by dividing by the standard deviation calculated over the same period. The PCA was performed on the subperiod 1951-2004, for which data availability is clearly greater.

Results of PCA show that 11 empirical orthogonal functions (EOF) account for more variance than the original variables (i.e., their eigenvalues are greater than 1) and that together explain more than $80 \%$ of the total variance of the dataset. We selected the first six EOF, which all have eigenvalues greater than $2(>3 \%$ of explained variance) and together explain more than $70 \%$ of the variance. These selected EOFs were rotated by means of a Varimax rotation, which produces stable and physically meaningful patterns.

In Fig. 2, the geographical representation of the loadings obtained from the PCA is plotted, allowing identifying the following regions:

1) Central east (CE; Fig. 2a): Southern half of Germany, the southern extreme of the Netherlands, the east of France, north of Switzerland, and most of Austria.

2) North central (NC; Fig. 2b): England, that is, the center and south of the British Islands.

3) Northeast (NE; Fig. 2c): Northern stations of WEU, that is, the north of Germany and a great part of the Netherlands.

4) Southwest (SW; Fig. 2d): Areas most influenced by the Mediterranean Sea, that is, most of the Iberian Peninsula and southeast of France.

5) Central west (CW; Fig. 2e): Most of France (the areas not included in other regions) and the northwest of the Iberian Peninsula.

6) Northwest (NW; Fig. 2f): Northern sectors of Great Britain and Ireland.

Subsequently, for each region we selected the stations that have their maximum loading in the corresponding EOF. By doing this, each station is univocally assigned to one region (see Fig. 1). Then, we computed the seasonal and annual mean regional series of SunDu. More specifically, as in SL07, the mean series are computed for the ratios between the values (annual or seasonal) and the mean over the 1961-90 period, at each station. These mean series allows a higher signal-tonoise ratio, enabling a better identification of long-term trends than single station series and reduce the possible bias due to time evolution of the number of available series. Although there are some stations with SunDu records that start as early as in the last decades of the nineteenth century, the low density of such stations and their nonhomogeneous distribution forced us to limit the extension only from 1938, according with the stipulation that at least three series were available within each region (Brunetti et al. 2006).

\section{Temporal behavior and trends of SunDu over western Europe}

The temporal changes of the above explained mean series are presented in Figs. 3 and 4. In both figures we 

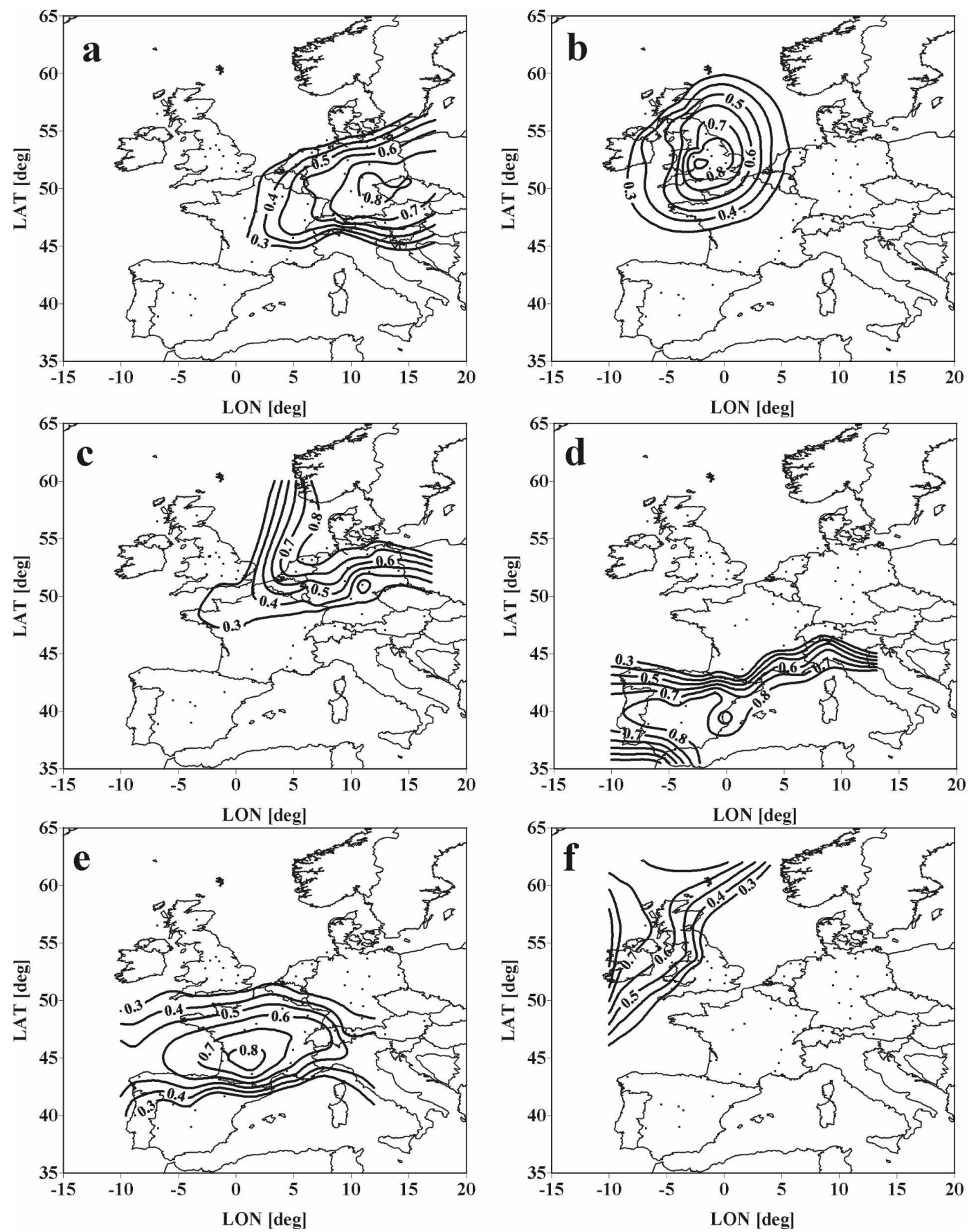

FIG. 2. (a)-(f) Geographical representation of the loadings of the first 6 rotated EOFs. Only contours for loadings greater that 0.3 are shown.

have included the line that corresponds to the series smoothed by an 11-yr window 3-yr $\sigma$ Gaussian low-pass filter, for a better visualization of the long-term and decadal variability. On the other hand, the overall trends of the series were calculated by least squares linear fitting, and their significances were evaluated with the Mann-Kendall nonparametric test (Table 1).
Although linear functions are not the best fit to all the temporal changes described by our data, they are commonly used for assessing general tendencies.

\section{a. Behavior of sunshine duration over entire WEU}

The WEU annual SunDu series (Fig. 3a) starts with an increasing tendency in the 1940s and reaches its 

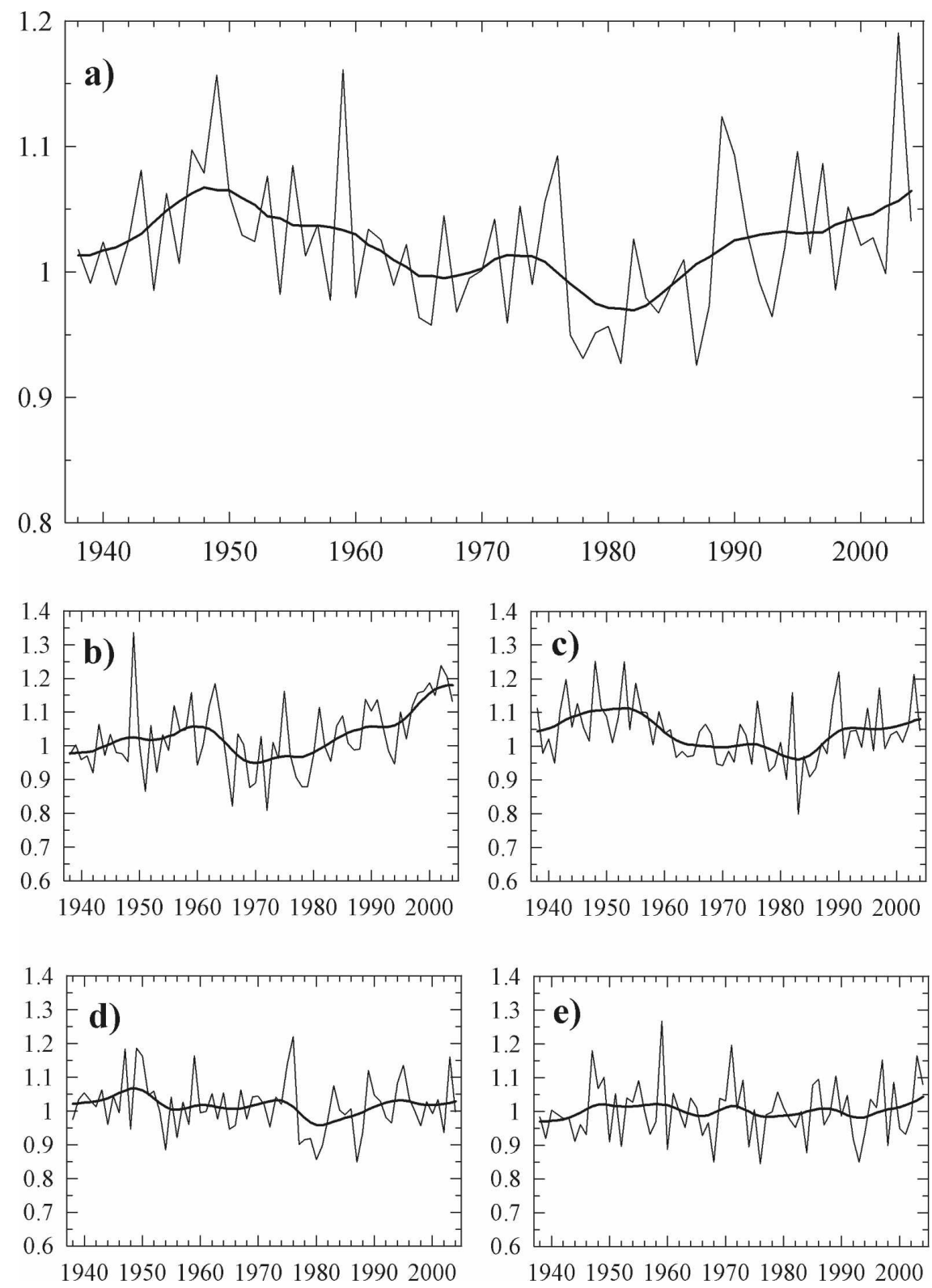

FIG. 3. Mean WEU sunshine duration series between 1938 and 2004 (thin line), plotted together with the 11-yr window 3-yr- $\sigma$ Gaussian low-pass filter (thick line): (a) annual; (b) winter; (c) spring; (d) summer; (e) autumn. The series are expressed as relative deviations from the 1961-90 mean.

maximum at the beginning of the 1950s. Afterward, this series shows a clear decrease of SunDu until the early 1980s, with a short period (between 1960 and 1970) of stabilization. Subsequently, SunDu recovers until the end of the analyzed period. The breakpoint between the dimming and the brightening tendencies is located around 1980, where 5 consecutive years (1977-81) have SunDu values around 5\% lower than the 1961-90 mean. The absolute minimum in the series is reached in 1987, while the maximum was recorded in 2003 . The overall linear trend of the annual SunDu series is slightly negative, but not significant.

As far as seasonal series are concerned, the winter series shows an initial increase in the first two decades followed by a decline in the $1960 \mathrm{~s}-70 \mathrm{~s}$, and a final rise until nowadays (Fig. 3b). A notable maximum is reached in 1949 and a minimum in 1972. Note that, in agreement with the recent SunDu increase, all years since 1997 show values greater than the 1961-90 mean. Regarding the long-term trend, we found a positive and 

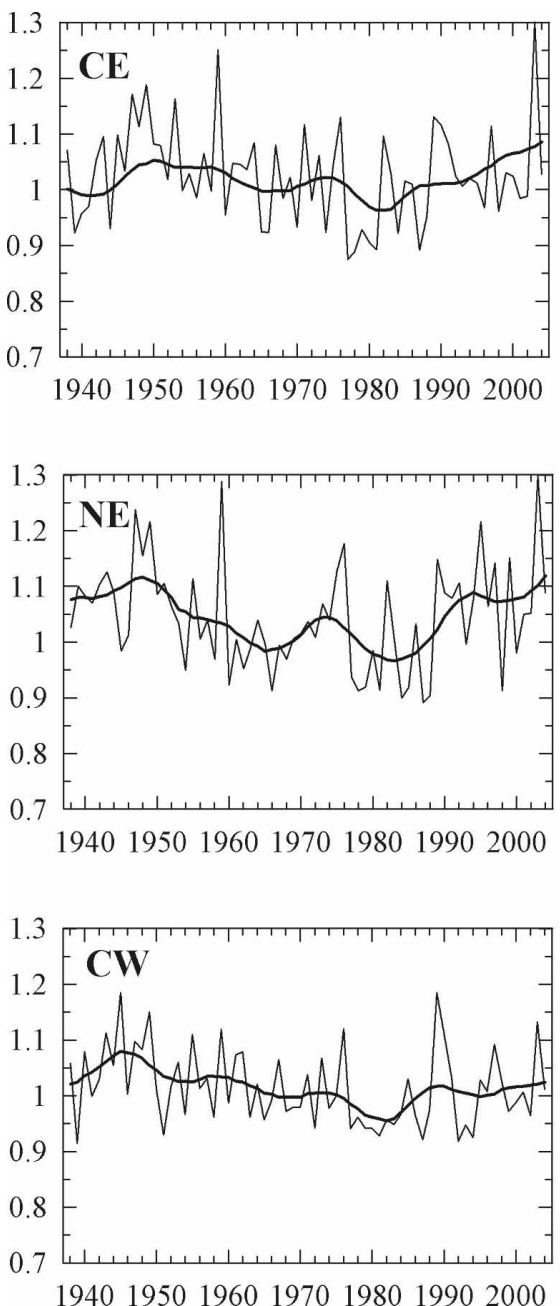
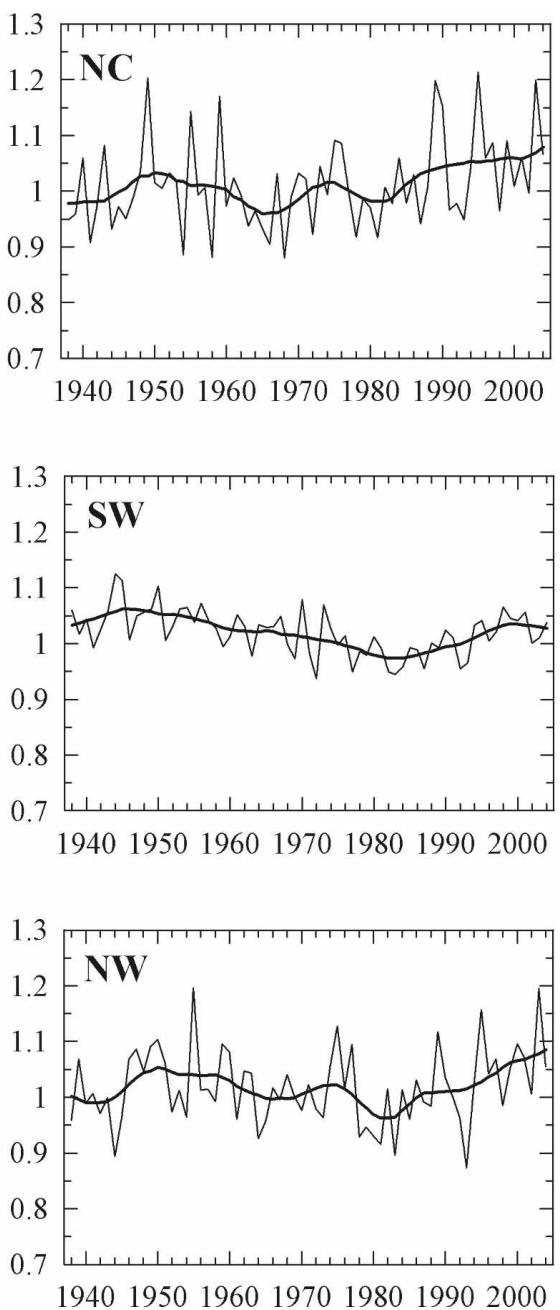

FIG. 4. As in Fig. 3, but for annual series for the six subregions.

significant trend of $+1.70 \%$ per decade for the winter series.

The temporal behavior of SunDu in spring is similar to the annual series (Fig. 3c), but the recent brightening does not compensate the strong decrease from the

TABLE 1. Linear trends of sunshine duration over the 1938-2004 period. Values are expressed in \% per decade. Bold values indicate trends with significance level higher than $99 \%$; italic values indicate trends with significance level higher than $95 \%$; other values with significance level greater than $90 \%$ are indicated, too; for lower levels of significance only the sign of the trend is indicated.

\begin{tabular}{lccccc}
\hline \hline Region & Annual & Winter & Spring & Summer & Autumn \\
\hline WEU & - & $\mathbf{1 . 7 0}$ & -0.85 & - & + \\
NW & + & + & - & - & + \\
NC & +1.01 & $\mathbf{+ 3 . 1 0}$ & - & + & $\mathbf{2 . 0 9}$ \\
NE & - & $\mathbf{+ 2 . 9 7}$ & - & - & + \\
CE & - & $\mathbf{+ 2 . 4 5}$ & - & - & - \\
CW & -0.86 & + & -2.14 & - & - \\
SW & $-\mathbf{0 . 8 6}$ & -1.39 & - & $-\mathbf{1 . 1 6}$ & -1.00 \\
\hline
\end{tabular}

1950s to the 1980s. The maximum value is reached in 1949 and the minimum in 1983 . Thus, the overall trend is negative, $-0.85 \%$ per decade, and significant.

In summer, SunDu has been much more stable during the analyzed period (Fig. 3d). Like in the annual series, there are 5 successive years with low values (1977-81) just after the maximum SunDu reached in 1976. The minimum of this series is found in 1987 and the overall trend is negative but nonsignificant.

Finally, the series corresponding to autumn is the most stable: other than the interannual variability, there are no noticeable changes (Fig. 3e). The maximum corresponds to 1959 , while the minimum record is found for 1976 . The overall trend is slightly positive but nonsignificant.

\section{b. Behavior of sunshine duration over the regions}

The annual series for all regions are plotted (Fig. 4) and described here; only the most remarkable charac- 
teristics of seasonal series are provided in the next paragraph. Taking the WEU as a reference, the most similar time evolutions are detected in regions $\mathrm{CE}$ and $\mathrm{NE}$, both showing also slightly negative trends that are nonsignificant. On the other hand, the NC and NW series start, as the WEU series, by an increasing tendency until the 1950s followed by a slight decrease until the late 1960s. Afterward, there is a positive trend till the end of the series, with a very short interruption in the second half of the 1970s. Their linear trends are positive, but only significant in the NC region $(+1.01 \%$ per decade). Finally, the SW and CW are also similar to the WEU series, although the recent increase of SunDu, after the absolute minimum at the beginning of the 1980s, does not compensate the previous decrease. Regarding long-term trends, the two latter regions show negative and significant values $(-0.86 \%$ per decade $)$.

Regarding the seasonal series, in winter, significant and positive trends of around $+3 \%$ per decade are found in the northern and eastern regions (CE, NC, $\mathrm{NE}$ ). The trends computed for other two regions (NW, $\mathrm{CW}$ ) are also positive, although nonsignificant. All these trends contribute toward the positive trend for the whole WEU despite of a noticeable negative and significant trend $(-1.39 \%$ per decade) for the southernmost region (SW). In spring, the only significant trend is detected in CW region $(-2.14 \%$ per decade), although in all other regions trends are also negative but nonsignificant. The summer series show again a noticeable opposite behavior between two regions: NC is the only region with a positive (nonsignificant) trend, while SW is the only with a significant negative trend $(-1.16 \%$ per decade). The same two regions are also noteworthy in autumn: they have the only significant trends, positive for $\mathrm{NC}(+2.09 \%$ per decade $)$ and negative for SW $(-1.00 \%$ per decade).

The decadal variability and the overall trends for region SW are in agreement with our previous results (SL07) for the Iberian Peninsula, where more series were used; this fact demonstrates that a limited number of SunDu series evenly distributed over an area may capture the regional climatic signal.

\section{c. Possible relation between SunDu evolution and changes in circulation patterns over WEU}

To try to explain the most interesting SunDu time evolutions, which correspond to winter and spring (both seasons have significant trends), we studied changes in the major atmospheric circulation patterns in Europe $\left(30^{\circ}-70^{\circ} \mathrm{N}, 40^{\circ} \mathrm{W}-40^{\circ} \mathrm{E}\right)$ over the $1938-2004$ period. The mean sea level pressure (SLP) data used is from Trenberth and Paolino (1980, updated) with a spatial resolution of $5^{\circ} \times 5^{\circ}$ grid. Unrotated PCA
(Preisendorfer 1988) was applied to the SLP seasonal anomalies, using the correlation matrix. Then, the scree test criterion was used to determine the maximum number of EOFs that can be considered well separated from each other. Subsequently, time series of these patterns were obtained with the principal component (PC) time series of the EOFs.

In winter, we selected 4 components that explain more than $86 \%$ of the total variance. In this case, the leading EOF explains more than $47 \%$ of total variance and shows the NAO circulation pattern over WEU (Fig. 5). The positive phase of this pattern is associated with surface westerlies across the middle latitudes of the Atlantic onto Europe, and with a reinforced anticyclonic situation over southern WEU. The PC time series of this pattern shows a significant (at $99 \%$ level) and positive correlation $(r=0.45)$ with the winter SunDu over WEU. Moreover, a clear increase of this pattern is detected from 1970s to the end of twentieth century (Hurrell and van Loon 1997), resulting in a positive significant trend (95\%) over the 1938-2004 period. Regarding the subregional series, the highest correlations were obtained for region SW $(r=0.57$, significant at the 99\% level) and CW ( $r=0.52,99 \%)$, while $\mathrm{CE}$ and $\mathrm{NC}$ show lower correlations $(0.37$ and 0.32 , respectively). Finally, NE regional series resulted not correlated with this pattern series, and the most northerly region (NW) turned to be negatively correlated $(r=-0.30,95 \%)$. These results confirm some previous findings, derived from shorter and lower spatial resolution data (Pozo-Vázquez et al. 2004), that established a highly significant positive (negative) correlation between the NAO index and the sunshine duration in southern (northern) Europe.

In spring, we also selected 4 EOFs that together explain more than $75 \%$ of the total variance. The leading EOF (not shown) presents the well-known spatial structure of the North Atlantic Oscillation (NAO), and its time series is significantly (at 99\% level) correlated $(r=0.41)$ with the WEU SunDu series, although the PC series does not present either a significant trend or a well-defined temporal change at decadal time scales. The most relevant result, however, is obtained with the third EOF, that has a significant (at 99\% level) correlation $(r=0.61)$ with the WEU SunDu series, and shows a similar time evolution (Fig. 5). The positive phase of this circulation pattern (Fig. 5) is defined by a high pressure system over central Europe and the British Islands that affects the whole WEU except the southwestern areas of the Iberian Peninsula. From the 1960s to 1980s a negative phase of the pattern can be detected, and consequently lower pressure is predominant over the WEU, maybe bringing more clouds and 

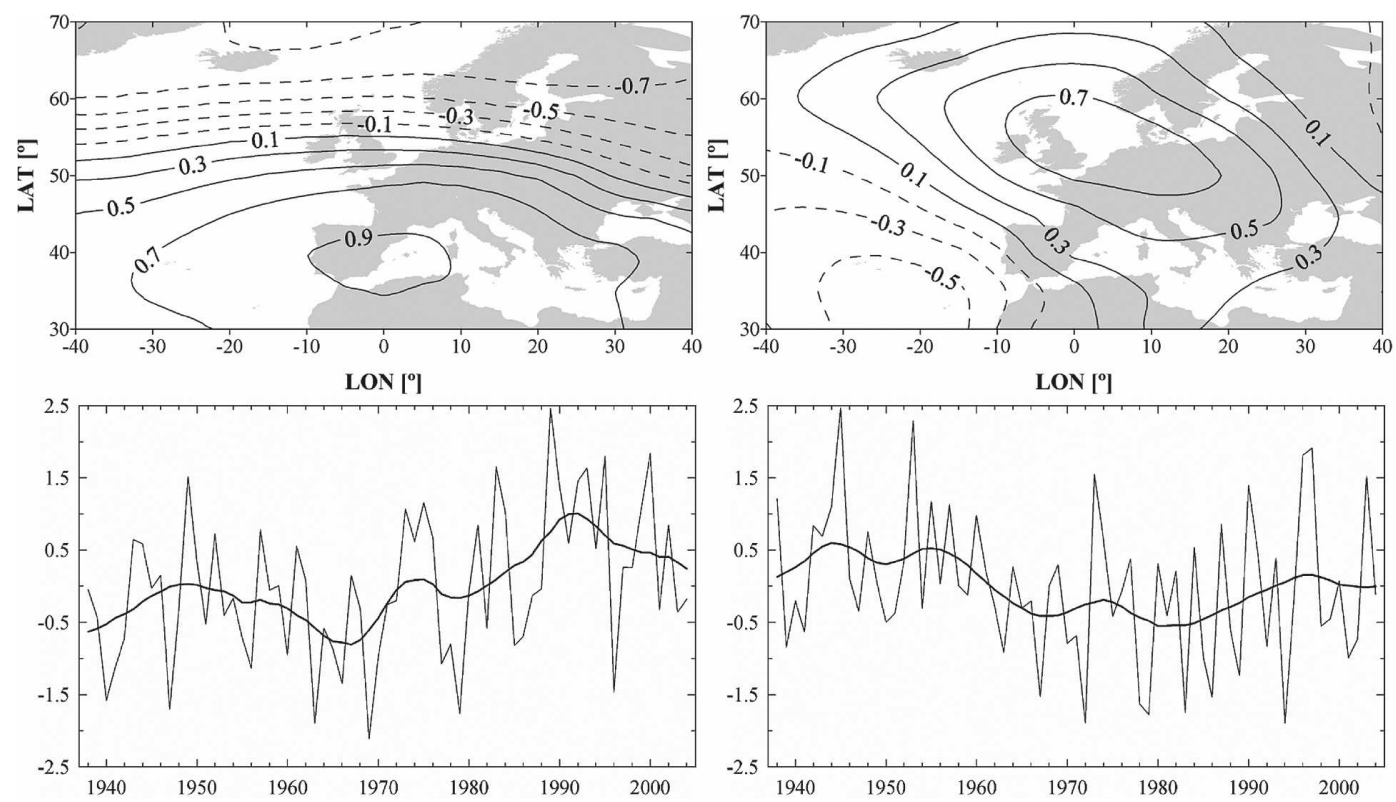

FIG. 5. (top) Surface level pressure for the represented EOF (left) number 1 for winter and (right) number 3 for spring. Negative loadings are dashed, the contour increment is 0.2 , and the zero contour has been omitted. (bottom) Temporal PC series for the corresponding EOF (thin line), plotted together with 11-yr window 3-yr- $\sigma$ Gaussian low-pass filter (thick line).

reducing the incoming solar radiation. The other two circulation patterns did not show significant trends either, and their time series are not correlated with the WEU SunDu.

\section{Discussion}

From the analyses of the temporal evolution of SunDu over the whole WEU, we confirm that the dimming (approximately in the period 1950-80) and the subsequent brightening (1980-2000), both observed worldwide and over Europe by other authors (Gilgen et al. 1998; Stanhill and Cohen 2001; Pinker et al. 2005; Wild et al. 2005), is also detectable in SunDu records. Thus, our results support the agreement between time evolution and trends of solar radiation measurements (Wild et al. 2005; Norris and Wild 2007) and the SunDu records over the WEU since the 1950s. This is in contrast with the results of Stanhill and Cohen (2005) for the United States, where a good correlation between both variables is stated, but a slightly different behavior during the analyzed period is found. On the other hand, the increasing sunshine duration in the 1940s is in disagreement with the constant decrease of the surface shortwave radiation downward flux estimated for the whole globe and also for Europe from simulations of the twentieth century with nine climate models (Romanou et al. 2007).

The reasons that explain the changes in SunDu are in general related to modifications in the atmospheric transmissivity resulting from changes in the shortwave radiative properties of the atmosphere, as well as to variations in cloud cover (Stanhill 2005). Regarding total cloud cover, Henderson-Sellers (1992) described a small increase from 1950s to 1960s, affecting the whole continent; while Warren et al. (2007) reported a clear decrease of cloud cover over Europe from 1971 to 1996. These two results are in general agreement with the presented SunDu temporal changes.

Regarding changes in transmissivity, it is very likely that they are the result of changes in the amount and type of anthropogenic aerosols released into the atmosphere. In fact, recent emission inventories of anthropogenic pollutants suggest that both scattering sulfur and absorbing black carbon aerosols showed large decreasing trends since the 1980s or 1990s, after decades of increase, due to effective air pollution regulation (Streets et al. 2006). Also, very recently Norris and Wild (2007) concluded that changes of cloud cover in Europe cannot explain the trends in the downward shortwave radiation flux, and consequently stated that the most likely explanation for these trends is related to changes in the scattered and absorbed solar radiation produced by changes in the anthropogenic aerosols emissions as already commented.

However, our results suggest that the dimming and brightening are mainly due to changes in one season (spring), with some contribution from winter. During 
spring, SunDu time evolution can be explained by possible cloudiness trends [which is in agreement with comments raised by the Intergovernmental Panel on Climate Change (IPCC) Fourth Assessment Report; Trenberth et al. 2007] related to changes in the atmospheric circulation. In particular, we have shown that there were more low pressure systems affecting most of WEU from 1960s to 1980s than in the last two decades.

The positive trend obtained from the winter mean series of the whole WEU is also found in five out of the six regions, although trends are significant only in three of them. These latter three regions correspond, approximately, to Austria, Germany, Switzerland, the Netherlands, and the center and south of the British Islands. It is possible that reductions in anthropogenic aerosol emissions, as previously commented, may explain part of the strong increase of SunDu since the 1970s until nowadays. Moreover, declining aerosol emission in winter are compatible with the effect of air pollution regulations on the use of some highly pollutant fuels formerly used in domestic heating. The sunshine duration recorder should be most sensitive to changes in aerosol concentration during winter because solar elevation is lowest in winter (Kaiser and Qian 2002). In addition, reductions of aerosol emissions should have a greater impact in winter, since this is the season with lower background aerosol loading (d'Almeida et al. 1991).

On the other hand, the positive trends of SunDu in winter can hardly be explained by the recent trend (since the 1970s) toward a positive NAO phase because correlation between NAO and SunDu for regions with positive SunDu trends in winter (NC, CE, and particularly NE) is low. In addition, there seems to be also a contradiction between the NAO trend toward a positive phase and the decline of SunDu in region SW, since higher values of the NAO index correspond to more stable conditions in the Iberian Peninsula, which should bring along reduced cloudiness. However, this latter contradiction could be solved if aerosols were the cause of reduced sunshine: note that anticyclonic conditions may induce longer residence times of the emitted aerosols. In this sense, note also that the reduction in aerosols emissions that has been achieved across the WEU may have not been reached yet in Spain (Roca et al. 2001), the country with most series in region SW.

\section{Conclusions}

In this paper we have presented the time evolution and trends of the sunshine duration over the western part of Europe, based on 79 series covering most of the twentieth century. The analyses were carried out on the annual and seasonal mean series calculated over the whole WEU and also for six regions identified by PCA, and were applied over the 1938-2004 period.

The temporal evolution of the mean annual series for the whole WEU shows a clear decrease in the sunshine duration from the 1950s until the early 1980s, followed by an increase until nowadays. This behavior is quite similar to what has been described in Europe as well as in other parts of the world as a "dimming" and the subsequent and recent "brightening." The mean series for spring shows a similar behavior, while in winter there is a clear significant increase of sunshine duration over the WEU, specially marked from 1970s.

The spring SunDu time evolution can be partly explained by changes in cloudiness related to changes in the atmospheric circulation over the same period. Contrarily, the regional behavior of the winter SunDu (with a significant increase limited to three regions- $\mathrm{CE}, \mathrm{NC}$, and $\mathrm{NE}$ - and a significant negative trend in the most southern region-SW) cannot be easily explained by the detected changes in circulation patterns, and therefore it must be related to different trends of anthropogenic aerosol emissions.

Acknowledgments. This research was supported by the Spanish Ministry of Education and Science (MEC) projects NUCLIER (CGL2004-02325/CLI) and NUCLIEREX (CGL2007-62664/CLI). Arturo Sanchez-Lorenzo was granted a FPU predoctoral scholarship by the same MEC. The sunshine duration series were provided by the European Climate Assessment \& Dataset Project, the Met Office (United Kingdom), and the Instituto Nacional de Meteorología (Spain). We thank Michele Brunetti and the two anonymous reviewers for their helpful comments.

\section{REFERENCES}

Aguilar, E., I. Auer, M. Brunet, T. C. Peterson, and J. Wieringa, 2003: Guidelines on climate metadata and homogenization. World Meteorological Organization Tech. Rep. WMO-TD 1186, 52 pp.

Alpert, P., P. Kishcha, Y. J. Kaufman, and R. Schwarzbard, 2005: Global dimming or local dimming? Effect of urbanization on sunlight availability. Geophys. Res. Lett., 32, L17802, doi:10.1029/2005GL023320.

Angell, J. K., 1990: Variation in United States cloudiness and sunshine duration between 1950 and the drought year of 1988. J. Climate, 3, 296-308.

Auer, I., and Coauthors, 2007: HISTALP-Historical instrumental climatological surface time series of the greater Alpine region. Int. J. Climatol., 27, 17-46.

Brázdil, R., A. A. Flocas, and H. S. Sahsamanoglou, 1994: Fluctuation of sunshine duration in central and South-Eastern Europe. Int. J. Climatol., 14, 1017-1034.

Brunetti, M., M. Maugeri, T. Nanni, I. Auer, R. Böhm, and W. 
Schöner, 2006: Precipitation variability and changes in the greater Alpine region over the 1800-2003 period. J. Geophys. Res., 111, D11107, doi:10.1029/2005JD006674.

Charlson, R. J., J. Langner, H. Rodhe, C. B. Leovy, and S. G. Warren, 1991: Perturbation of the North Hemisphere radiative balance by backscattering from anthropogenic sulfate aerosols. Tellus, 43AB, 152-163.

d'Almeida, G. A., P. Koepke, and E. P. Shettle, 1991: Atmospheric Aerosols: Global Climatology and Radiative Characteristics. A. Deepak, $561 \mathrm{pp}$.

Gilgen, H., M. Wild, and A. Ohmura, 1998: Means and trends of shortwave irradiance at the surface estimated from Global Energy Balance Archive data. J. Climate, 11, 2042-2061.

Henderson-Sellers, A., 1992: Continental cloudiness changes this century. GeoJournal, 27, 255-262.

Hurrell, J. W., and H. van Loon, 1997: Decadal variations in climate associated with the North Atlantic Oscillation. Climatic Change, 36, 301-326.

Kaiser, D. P., and Y. Qian, 2002: Decreasing trends in sunshine duration over China for 1954-1998: Indication of increased haze pollution? Geophys. Res. Lett., 29, 2042, doi:10.1029/ 2002 GL016057.

Klein Tank, A. M. G., and Coauthors, 2002: Daily dataset of 20th-century surface air temperature and precipitation series for the European climate assessment. Int. J. Climatol., 22, $1441-1453$

Liepert, B. G., 2002: Observed reductions of surface solar radiation at sites in the United States and worldwide from 1961 to 1990. Geophys. Res. Lett., 29, 1421, doi:10.1029/ 2002GL014910.

Norris, J. R., and M. Wild, 2007: Trends in aerosol radiative effects over Europe inferred from observed cloud cover, solar "dimming," and solar "brightening." J. Geophys. Res., 112, D08214, doi:10.1029/2006JD007794.

Pinker, R. T., B. Zhang, and E. G. Dutton, 2005: Do satellites detect trends in surface solar radiation? Science, 308, 850 854.

Pozo-Vázquez, D., J. Tovar-Pescador, S. R. Gámiz-Fortis, M. J. Esteban-Parra, and Y. Castro-Díez, 2004: NAO and solar radiation variability in the European North Atlantic region. Geophys. Res. Lett., 31, L05201, doi:10.1029/2003GL018502.

Preisendorfer, R. W., 1988: Principal Component Analysis in Meteorology and Oceanography. Elsevier, $425 \mathrm{pp}$.

Ramanathan, V., P. J. Crutzen, J. T. Kiehl, and D. Rosenfeld, 2001: Aerosols, climate, and the hydrological cycle. Science, 294, 2119-2124.

Roca, J., E. Padilla, M. Farré, and V. Galletto, 2001: Economic growth and atmospheric pollution in Spain: Discussing the environmental Kuznets curve hypothesis. Ecol. Econ., 39, 8599.

Romanou, A., B. Liepert, G. A. Schmidt, W. B. Rossow, R. A. Ruedy, and Y. Zhang, 2007: 20th century changes in surface solar irradiance in simulations and observations. Geophys. Res. Lett., 34, L05713, doi:10.1029/2006GL028356.

Sanchez-Lorenzo, A., M. Brunetti, J. Calbó, and J. Martin-Vide, 2007: Recent spatial and temporal variability and trends of sunshine duration over the Iberian Peninsula from a homogenized dataset. J. Geophys. Res., 112, D20115, doi:10.1029/ 2007JD008677.

Stanhill, G., 2005: Global dimming: A new aspect of climate change. Weather, 60, 11-14

- 2007: A perspective on global warming, dimming, and brightening. Eos, Trans. Amer. Geophys. Union, 88, 58-59.

- and S. Cohen, 2001: Global dimming: A review of the evidence for a widespread and significant reduction in global radiation with discussion of its probable causes and possible agricultural consequences. Agric. For. Meteor., 107, 255-278.

— and _ 2005: Solar radiation changes in the United States during the twentieth century: Evidence from sunshine duration measurements. J. Climate, 18, 1503-1512.

Streets, D. G., Y. Wu, and M. Chin, 2006: Two-decadal aerosol trends as a likely explanation of the global dimming/ brightening transition. Geophys. Res. Lett., 33, L15806, doi:10.1029/2006GL026471.

Trenberth, K. E., and D. A. Paolino, 1980: The Northern Hemisphere sea-level pressure data set: Trends, errors, and discontinuities. Mon. Wea. Rev., 108, 855-872.

- , and Coauthors, 2007: Observations: Surface and atmospheric climate change. Climate Change 2007: The Physical Science Basis, S. Solomon et al., Eds., Cambridge University Press, 235-336.

Warren, S. G., R. M. Eastman, and C. J. Hahn, 2007: A survey of changes in cloud cover and cloud types over land from surface observations, 1971-96. J. Climate, 20, 717-738.

Wheeler, D., 2001: Factors governing sunshine in south-west Iberia: A review of western Europe's sunniest region. Weather, 56, 189-197.

Wild, M., and Coauthors, 2005: From dimming to brightening: Decadal changes in solar radiation at earth's surface. Science, 308, 847-850.

, A. Ohmura, and K. Makowski, 2007: Impact of global dimming and brightening on global warming. Geophys. Res. Lett., 34, L04702, doi:10.1029/2006GL028031. 